\title{
A Joint Positioning and Attitude Solving Method for Shearer and Scraper Conveyor under Complex Conditions
}

\author{
Jiacheng Xie, ${ }^{1,2}$ Zhaojian Yang, $^{1,2}$ Xuewen Wang, ${ }^{1,2}$ Shuping Wang, ${ }^{1,2}$ and Qing Zhang \\ ${ }^{1}$ College of Mechanical Engineering, Taiyuan University of Technology, Taiyuan, China \\ ${ }^{2}$ Shanxi Key Laboratory of Fully Mechanized Coal Mining Equipment, Taiyuan, China \\ Correspondence should be addressed to Zhaojian Yang; yangzhaojian@tyut.edu.cn
}

Received 7 July 2017; Accepted 24 September 2017; Published 26 October 2017

Academic Editor: Michael Defoort

Copyright (c) 2017 Jiacheng Xie et al. This is an open access article distributed under the Creative Commons Attribution License, which permits unrestricted use, distribution, and reproduction in any medium, provided the original work is properly cited.

\begin{abstract}
In a fully mechanized coal-mining face, the positioning and attitude of the shearer and scraper conveyor are inaccurate. To overcome this problem, a joint positioning and attitude solving method that considers the effect of an uneven floor is proposed. In addition, the real-time connection and coupling relationship between the two devices is analyzed. Two types of sensors, namely, the tilt sensor and strapdown inertial navigation system (SINS), are used to measure the shearer body pitch angle and the scraper conveyor shape, respectively. To improve the accuracy, two pieces of information are fused using the adaptive information fusion algorithm. It is observed that, using a marking strategy, the shearer body pitch angle can be reversely mapped to the real-time shape of the scraper conveyor. Then, a virtual-reality (VR) software that can visually simulate this entire operation process under different conditions is developed. Finally, experiments are conducted on a prototype experimental platform. The positioning error is found to be less than 0.38 times the middle trough length; moreover, no accumulated error is detected. This method can monitor the operation of the shearer and scraper conveyor in a highly dynamic and precise manner and provide strong technical support for safe and efficient operation of a fully mechanized coal-mining face.
\end{abstract}

\section{Introduction}

As a key equipment of a fully mechanized coal-mining face, the shearer plays a pivotal role in the coal production process. The positioning and attitude information of the shearer determines the state of the corresponding scraper conveyor [1-3] and the corresponding hydraulic supports [4]; therefore, monitoring and determination of the shearer's running information are of significance with regard to realizing automated operation of three machines $[5,6]$. The scraper conveyor mainly completes tasks such as transporting and shipping out cutting coal, running orbit of shearer, overall pushing to the coal wall side with other corresponding equipment, and coupling with the floor in real time. Therefore, the real-time shape of the scraper conveyor is the key link between the uneven floor and the shearer position and attitude information.
To date, a few attempts have been made to detect the change in the topography and fluctuation range of the floor using tilt sensors installed in the shearer body [7]. Based on real-time detection results obtained for pitch and roll angles, the cutting height was compensated in the process of shearer memory cutting [7]. However, the shearer body pitch angle was the connecting line of the two supporting sliding shoes, whose distance was four-to-six times the middle trough length. It was easy to neglect the variation in coal seam between the two supporting sliding shoes; therefore, the floor described by the shearer body pitch angle was not reliable owing to the nonsensitivity character in the uneven floor [8].

Wu et al. $[9,10]$ obtained an accurate changing trend of the floor by installing tilt sensors in every middle trough. This improved the coupling degree of the scraper conveyor and the uneven floor. In general, in the advancing direction of the working face, the height of the roof and 
floor changed slowly. Mutations will only appear when encountering geological structures such as faults and folds. However, with gradual changes in the roof and floor, the accumulation of circular errors led to inaccurate positioning and attitude calculation for the shearer [11, 12]. Xu [13] put forward a three-dimensional (3D) positioning theory that adopted the strategy of integrating stability and movement. On the premise of being in the same diagonal of the supporting points of the two supporting sliding shoes, Liu and Chen [14] established a digital model of the coal roof and floor. Su et al. [15] established a mathematical model of the profile cutting of the shearer. Ge [16] proposed a $3 \mathrm{D}$ fine geological model that enabled the shearer to adapt to complex terrain structures such as faults and folds. Based on the real-time dynamic correction strategy, Feng [17] obtained the floor curve using a shearer kinematics model.

However, the above-mentioned studies were not universal to every condition owing to the idealization of the assumed conditions and nonconsideration of the coupling relationship between the scraper conveyor and shearer.

Regarding the positioning of the shearer, significant research progress has been made [18-22]. This includes the development of some accurate fusion positioning methods such as SINS and encoders [23-25], wireless sensor networks [26-28], infrared cameras [29], and geographic information systems [30], which yielded remarkable results; however, these methods are still in the theoretical research stage and are not yet used in industrial applications.

To overcome this barrier, Zhang et al. [31] proposed a method to detect the layout inspection of the scraper conveyor on the basis of the running trajectory and precise positioning of the shearer. This method efficiently reproduced the theoretical results. However, the shearer prototype was driven by four small wheels, and the scraper conveyor prototype was relatively simple and could not reflect the connection between the actual shearer and actual scraper conveyor efficiently. Owing to the unique and complex characteristics of the underground environment, it was difficult to conduct a physical experiment.

In some laboratories, because of the heavy equipment of the fully mechanized mining system and inability to create real uneven-floor conditions, it is difficult to verify the correctness of the method. Therefore, a prototype of the shearer and scraper conveyor must be designed to simulate the underground working conditions.

In this paper, to overcome the abovementioned problems, a joint positioning and attitude solving method for shearer and scraper conveyor is investigated under complex conditions.

\section{Theoretical Analysis}

2.1. Related Concepts of Shearer and Scraper Conveyor. The entire coordination process of three machines in a fully mechanized coal-mining face is in accordance with the shearer location and relevant regulations. As shown in Figure 1, the shearer walks on the flexible scraper conveyor and cuts the coal.
In the process of shearer running, the coal plate comes into contact with the left and right supporting sliding shoes in the middle trough and the left and right walking wheels are meshed with the pin rails of the middle trough.

Therefore, there are two meshing relationships, namely, the coupling relationship between the walking wheels and shape of pin rails and that between the supporting sliding shoes and coal plate. These two relationships directly affect the shearer pitch angle; therefore, it is necessary to analyze the coupling relationship between the two groups.

The pin rails are divided into two categories: the middle pin rails and the connecting pin rails. Each pin rail connects to the corresponding middle trough with two pin shafts. The middle pin rails move with the corresponding middle trough and keep the same center position of the corresponding middle trough. Meanwhile, the connecting pin rails change correspondingly according to the horizontal inclination angle.

2.2. Overall Design and Layout of Sensors. Some double-axis tilt sensors are installed in each middle trough to obtain the horizontal and vertical inclination angle of each middle trough in real time (Figure 2).

2.3. Overall Framework. In this paper, the connecting and coupling relationship between the shearer and scraper conveyor is developed under complex conditions using the sensors installed in the equipment. The general method is as follows (Figure 3):

(1) The horizontal and vertical inclination angles of each middle trough are obtained using double-axis tilt sensors arranged on each middle trough; therefore, the shape of the scraper conveyor can be determined.

(2) The shapes of the coal plate and the pin rails can be obtained on the basis of the analytical results obtained for a middle trough structure.

(3) By setting the left supporting sliding shoe as the positioning point of the shearer, when the shearer is at a position corresponding to a position in the scraper conveyor, the contacting mode of the two supporting sliding shoes and the coal plate is assessed and the key point coordinate of the left supporting sliding shoe is obtained.

(4) The key point coordinate of the right supporting sliding shoe is obtained using the exhaustion method.

(5) The shearer body pitch angle is solved by connecting the key points of the two supporting sliding shoes.

(6) The key points of two walking wheels are determined by the key point coordinates of the two supporting sliding shoes, and the shearer body pitch angle is determined on the basis of the left and right walking wheels and pin rails.

(7) Taking the above-mentioned point as prior knowledge, the actual real-time shearer body pitch angle obtained using tilt sensors and SINS is reversely 


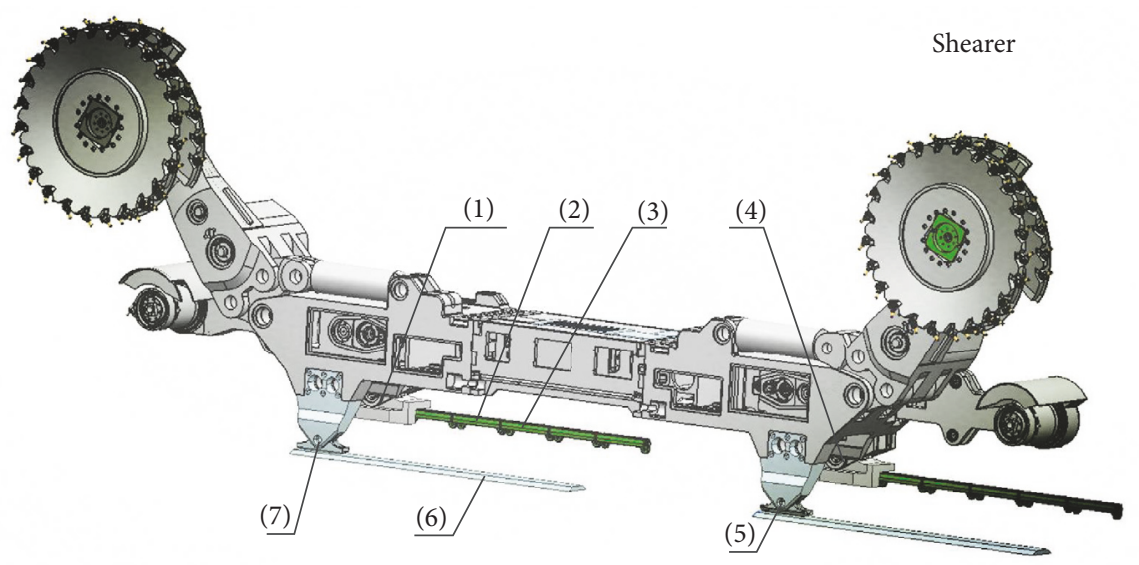

Scraper conveyor

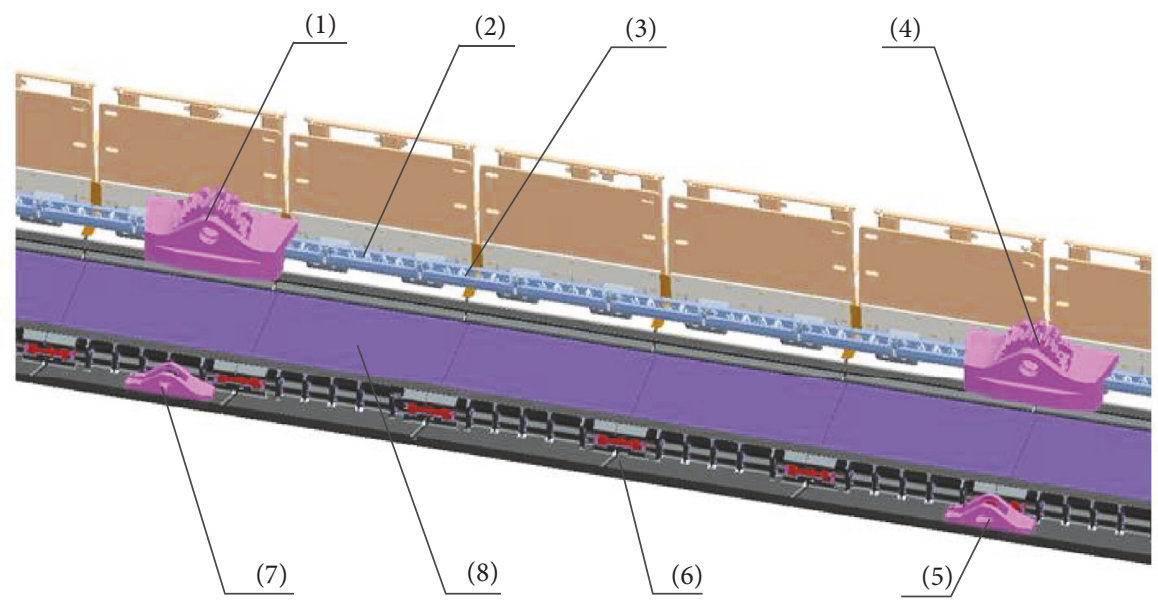

FIGURE 1: Related concepts of shearer and conveyor scraper. (1) Left walking wheel; (2) middle pin rails; (3) connecting pin rails; (4) right walking wheel; (5) right supporting sliding shoe; (6) coal plate; (7) left supporting sliding shoe; (8) middle rough.

mapped to the shape of the scraper conveyor in the actual operation process; thus, the shearer's walking distance and position relative to the scraper conveyor can be obtained.

\subsection{Positioning and Attitude Solving Method for Shearer and Scraper Conveyor}

2.4.1. Positioning and Attitude Solving Method for Shearer. The shearer attitude described by the several key points shown in Figure 2 can be obtained using sensors installed in the shearer body. When a vertical inclination angle exists, the coordinates of these key points can be easily calculated by converting and correcting all angles.

2.4.2. Positioning and Attitude Solving Method for Scraper Conveyor. Suppose that the length of the middle trough is $L_{Z B C}$ and the horizontal and vertical inclination angles of the middle trough $n$ are $\alpha_{n}$ and $\beta_{n}$, respectively.
A piecewise function of the middle troughs in the $X Y$ plane (Figure 4) can be expressed as follows:

$$
\begin{gathered}
f_{1}(x)=x \tan \alpha_{1}, \quad 0 \leq x \leq x_{1} \\
f_{2}(x)=f_{1}\left(x_{1}\right)+\left(x-x_{1}\right) \tan \alpha_{2}, \quad x_{1}<x \leq x_{2} \\
\vdots \\
f_{n-1}(x)=f_{n-2}\left(x_{n-2}\right)+\left(x-x_{n-2}\right) \tan \alpha_{n-1}, \\
x_{n-2}<x \leq x_{n-1} \\
f_{n}(x)=f_{n-1}\left(x_{n-1}\right)+\left(x-x_{n-1}\right) \tan \alpha_{n}, \quad \\
x_{n-1}<x \leq x_{n},
\end{gathered}
$$

where $x_{i}$ is the boundary point of the middle trough $i$ in the $X$ coordinate.

By setting the key point $O 1$, which is located at the $p$ position of the middle trough $k, s / L_{Z B C}=k \cdots p$, where $s$ is the shearer walking length relative to the scraper conveyor, 


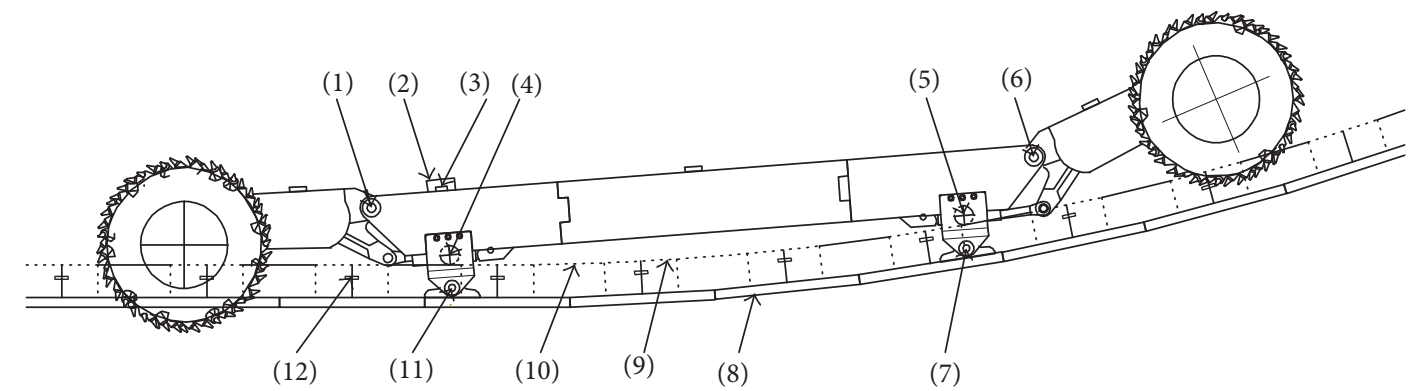

FIGURE 2: Connection relationship between the shearer and scraper conveyor and sensor arrangement. (1) Hinge point of the left arm and body (characteristic point $E_{1}$ ); (2) tilt sensors installed in the shearer body; (3) SINS device; (4) key point of the left walking wheel (characteristic point $D_{1}$ ); (5) key point of the right walking wheel (characteristic point $D_{2}$ ); (6) hinge point of the right arm and body (characteristic point $\left.E_{2}\right)$; (7) key point of the right supporting sliding shoe (characteristic point $\mathrm{O}_{2}$ ); (8) coal plate; (9) middle pin rails; (10) connecting pin rails; (11) key point of the left supporting sliding shoe (characteristic point $O_{1}$ ); (12) double-axis tilt sensor installed in every middle trough.

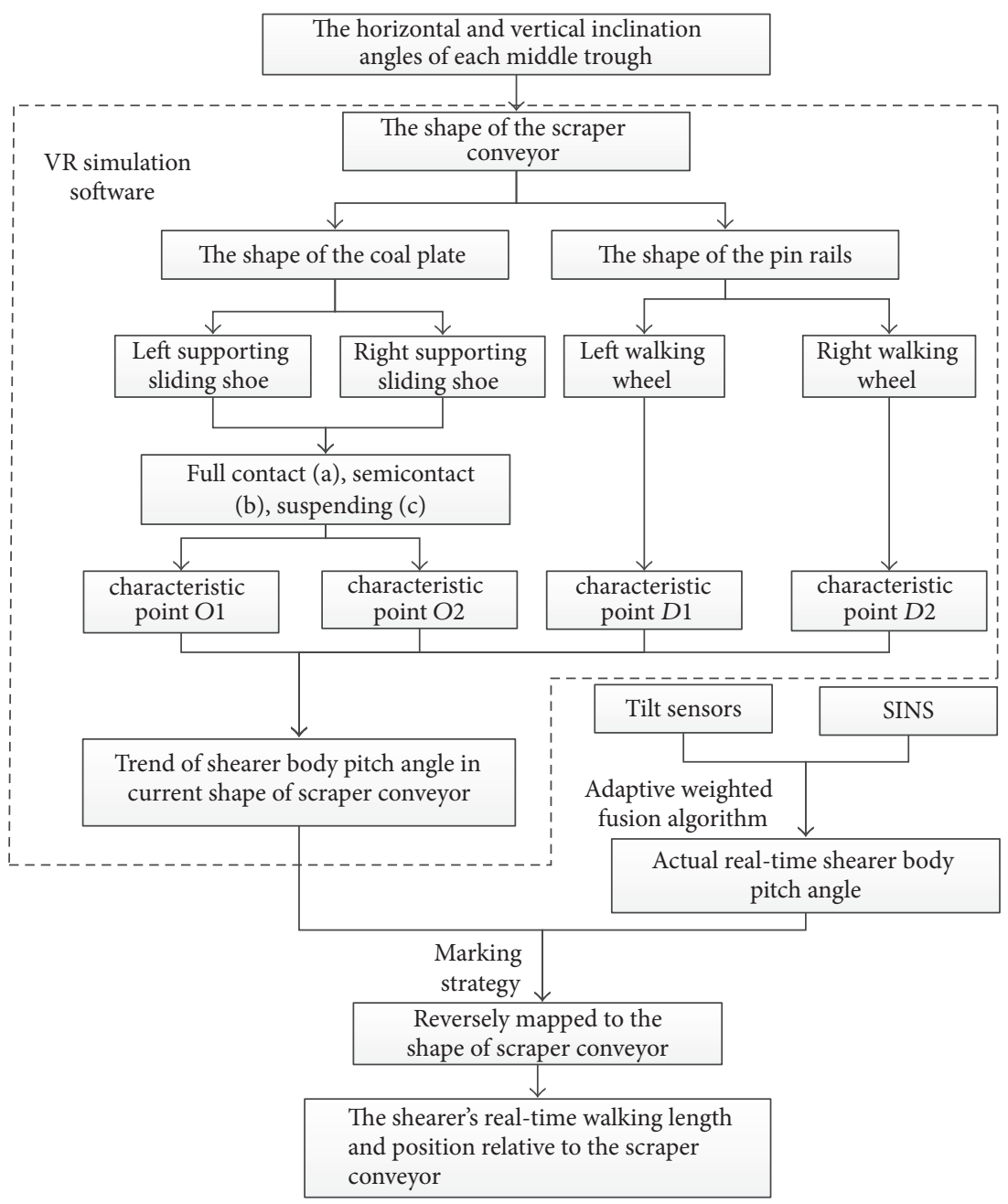

Figure 3: Research process.

$k$ is the serial number of the middle trough, and $p$ is the position of the middle trough $k,\left(x_{k}, y_{k}\right)$ and $\left(x_{p}, y_{p}\right)$ can be calculated. Here, $\left(x_{k}, y_{k}\right)$ is the coordinate of hinge joint $k$ of the scraper conveyor and $\left(x_{p}, y_{p}\right)$ is the coordinate offset of the $p$ position of scraper conveyor $k$, relative to the point $\left(x_{k}\right.$, $\left.y_{k}\right)$.

Therefore, if the running distance is $s$, the coordinates can be expressed as follows: 


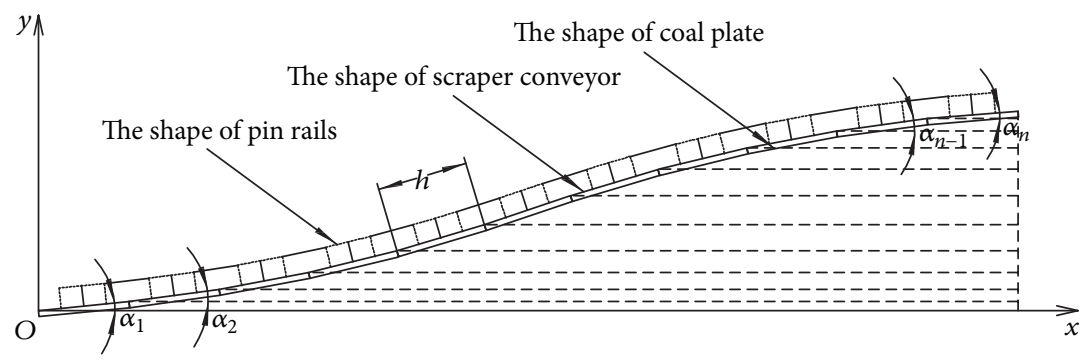

FIGURE 4: Shape of a scraper conveyor.

$$
\begin{aligned}
& x_{s}=x_{k}+x_{p}=L_{Z B C} \sum_{i=1}^{k} \cos \alpha_{i}+L_{Z B C} * p * \cos \alpha_{k+1} \\
& y_{s}=y_{k}+y_{p}=L_{Z B C} \sum_{i=1}^{k} \sin \alpha_{i}+L_{Z B C} * p * \sin \alpha_{k+1} .
\end{aligned}
$$

\subsection{Analysis of Coupling Positioning and Attitude Relationship between the Shearer and Scraper Conveyor}

\subsubsection{Coupling Relationship between Supporting Sliding Shoes and Coal Plate}

(1) Contacting Modes of Supporting Sliding Shoes and Coal Plates. The shearer body pitch angle reflects the fluctuation degree between the left and the right supporting sliding shoes. Based on a theoretical analysis, we obtained three contacting modes between the supporting sliding shoes and coal plate, as shown in Figure 5:

(a) Full contact: the base line of the supporting sliding shoe is parallel to the coal plate.

(b) Semicontact: the supporting sliding shoe is at the intersection position of the two adjacent middle troughs and can only come into contact with one middle trough. (c) Suspending: the supporting sliding shoe is at the intersection position of the two adjacent middle troughs and cannot come into full contact with any of the two middle troughs.

The determination rule of the contacting mode is shown in Table 1.

Points $A, B$, and $O$ are the left, right, and middle points of the base line of the supporting sliding shoes, respectively; $\mathrm{Na}$, $\mathrm{Nb}$, and No are the serial numbers of the middle trough that points $A, B$, and $C$ belong to, respectively; and FloatHA[ $i]$ is the horizontal inclination angle of the middle trough $i$.

(2) Analysis of the Contacting Mode between the Support Sliding Shoes and Coal Plate. There are three contacting modes between the supporting sliding shoes and the coal plate. Taking the semicontact case, which is the most complex condition, as an example, the shearer attitude and position parameters can be obtained using the following method. This method is known as the suspending solving algorithm and its parameters are shown in Figure 6 , where $X_{A}, X_{B}, \theta_{1}$, and $\theta_{2}$ are unknown parameters and $L_{H}$ and $\varepsilon$ are structural parameters. Among them, $\mathrm{Na}=p$ and $\mathrm{Nb}=p+1$.

According to the relationship, we can list the following equations:

$$
\begin{aligned}
X_{B}-X_{A} & =\left(2 L_{H} \cos \varepsilon\right) * \cos \left(\theta_{1}+\alpha_{p}\right) \\
X_{\mathrm{O} 1}-X_{A} & =L_{H} \cos \left(\varepsilon+\theta_{1}+\alpha_{p}\right) \\
\frac{\left(X_{B}-X_{C}\right) / \cos \alpha_{p+1}}{\sin \theta_{1}} & =\frac{2 L_{H} \cos \varepsilon}{\sin \left(\pi-\left(\alpha_{p+1}-\alpha_{p}\right)\right)} \\
M_{1} & =\frac{-2 * L_{H} * \cos (\varepsilon) * \sin \left(\alpha_{p}\right)+L_{H} * \sin \left(\varepsilon+\alpha_{p}\right)-C * \cos \left(\alpha_{p+1}\right)}{X_{C}-X_{\mathrm{O} 1}} \\
M_{2} & =\frac{2 * L_{H} * \cos (\varepsilon) * \cos \left(\alpha_{p}\right)-L_{H} * \sin \left(\varepsilon+\alpha_{p}\right)}{X_{C}-X_{O 1}} \\
M_{3} & =\frac{2 * L_{H} * \cos (\varepsilon)}{\sin \left(\alpha_{p+1}-\alpha_{p}\right)} \\
\gamma & =\arcsin \left(\frac{M_{2}}{\sqrt{M_{1}^{2}+M_{2}^{2}}}\right)
\end{aligned}
$$


TABLE 1: Determination rule of the contacting mode.

\begin{tabular}{|c|c|c|c|}
\hline Mode & Meaning & Condition & Calculation angle \\
\hline 0 & $\begin{array}{l}\text { Full contact, the supporting sliding shoe is } \\
\text { fully located in a middle trough }\end{array}$ & $\begin{array}{c}\text { (1) } \mathrm{Na}=\mathrm{Nb} \\
\text { (2) } \mathrm{Na} \neq \mathrm{Nb} \text { and FloatHA[Na] = FloatHA[Nb] }\end{array}$ & $\mathrm{Na}$ \\
\hline 10 & $\begin{array}{c}\text { Semicontact, in the range of the middle } \\
\text { trough } \mathrm{Na}\end{array}$ & $\begin{array}{c}\text { (1) } \mathrm{Na} \neq \mathrm{Nb} \text { and } \mathrm{Na}=\mathrm{No}_{1} \text {, FloatHA[Na] }> \\
\text { FloatHA[Nb] }\end{array}$ & $\mathrm{Na}$ \\
\hline 11 & $\begin{array}{l}\text { Semicontact, in the range of the middle } \\
\text { trough } \mathrm{Nb}\end{array}$ & $\begin{array}{c}\text { (1) } \mathrm{Na} \neq \mathrm{Nb} \text { and } \mathrm{Nb}=\mathrm{No}_{1} \text {, FloatHA[Na] }> \\
\text { FloatHA[Nb] }\end{array}$ & $\mathrm{Nb}$ \\
\hline 2 & Suspending & (1) $\mathrm{Na} \neq \mathrm{Nb}$ and FloatHA[Na] $<$ FloatHA[Nb] & $\begin{array}{c}\text { Suspending solving } \\
\text { algorithm }\end{array}$ \\
\hline
\end{tabular}

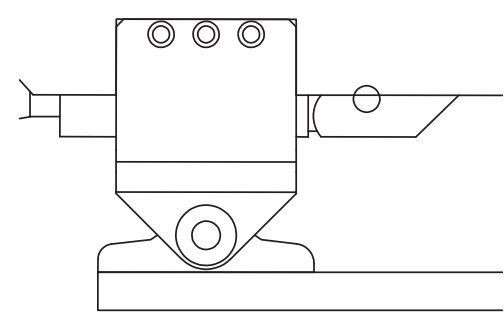

(a)

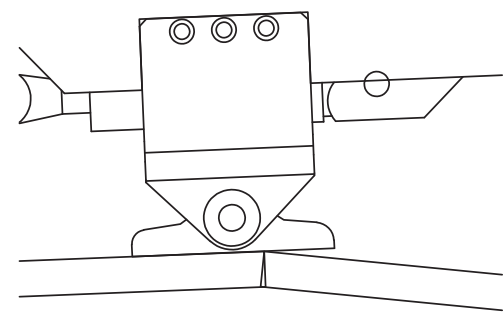

(b)

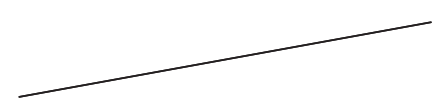

FIGURE 5: Contacting model between the supporting sliding shoes and coal plate.

where $M_{1}, M_{2}$, and $M_{3}$ are the three middle variables and $\gamma$ is the middle angle.

Solution:

$$
\begin{aligned}
\theta_{1}= & \frac{\pi}{2}-\gamma \\
X_{A}= & X_{O 1}-L_{H} \cos \left(\theta_{1}+\alpha_{p}+\beta\right) \\
X_{B}= & X_{O 1}+2 L_{H} \cos \beta * \cos \left(\theta_{1}+\alpha_{p}\right) \\
& -L_{H} \cos \left(\theta_{1}+\alpha_{p}+\beta\right) .
\end{aligned}
$$

So $Y_{\mathrm{O} 1}$ can be expressed as follows:

$$
\begin{aligned}
& Y_{\mathrm{O} 1} \\
& \quad= \begin{cases}f\left(X_{A}\right)+L_{H} \sin \left(\theta_{1}+\alpha_{p}+\beta\right) & N_{O 1}=p \\
f\left(X_{A}\right)+L_{H} \sin \left(\theta_{1}+\alpha_{p+1}+\beta\right) & N_{O 1}=p+1,\end{cases}
\end{aligned}
$$

where, for $N_{\mathrm{O} 1}$, the number of middle troughs it belongs to must be determined.

(3) Shearer Body Pitch Angle. After determining the condition of the left supporting sliding shoe, the condition of the right supporting sliding shoe must be assessed.

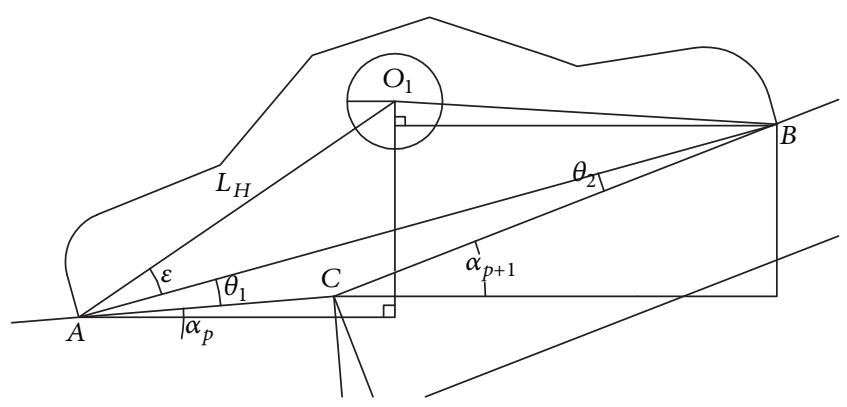

FIgure 6: Analysis under semicontact condition.

Point $\mathrm{O} 2$ coordinates can be solved by the following formula:

$$
\begin{aligned}
& X_{\mathrm{O} 2}=X_{\mathrm{O} 1}+L_{j s} \cos \alpha_{j s} \\
& Y_{\mathrm{O} 2}=Y_{\mathrm{O} 1}+L_{j s} \sin \alpha_{j s},
\end{aligned}
$$

where $\alpha_{j s}$ is the shearer body pitch angle and $L_{j s}$ is the shearer body length (the connection length between point D1 and point D2).

There are nine possible conditions under which the contacting mode of the two supporting sliding shoes is considered simultaneously. 


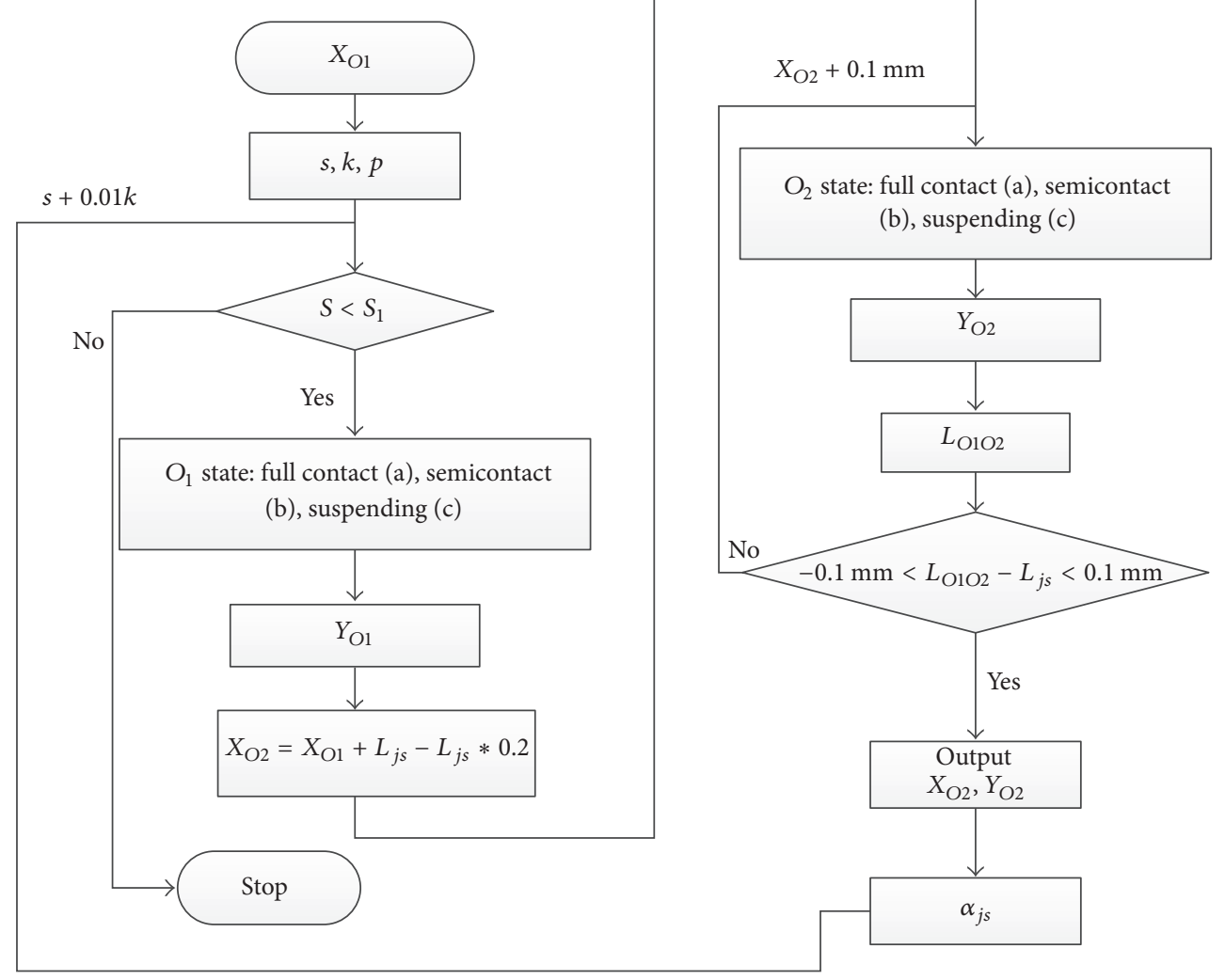

FIgURE 7: Flow chart of the solving method.

Owing to the difficulty in calculating the condition of the right sliding shoe using a direct method, the indirect calculation method is used, as shown in Figure 7.

In Figure 7, $S_{1}$ is the limit position of the shearer walking on the scraper conveyor.

When the $X_{O 1}$ coordinate increases the distance to 0.8 times the length of the shearer body, the $X_{\mathrm{O} 2}$ coordinate can be analyzed and the contacting mode can be assessed. Thereby, the corresponding algorithm was used to solve the problem.

Based on the condition of the distance and the shearer body length, the $X_{\mathrm{O} 2}$ coordinates were assessed by comparing the $X_{O 1}$ coordinates. If an error exists in a small range, the solution would be correct. If an error does not fall within this range, the unit operation length would be increased to the $X_{\mathrm{O} 2}$ coordinates and assessment would continue until the condition was satisfied and the correct $\mathrm{O} 2$ point coordinates could be solved.

Therefore, the shearer body pitch angle could be calculated as follows:

$$
\alpha_{j s}=\tan \frac{Y_{\mathrm{O} 2}-Y_{\mathrm{O} 1}}{X_{\mathrm{O} 2}-X_{\mathrm{O} 1}} .
$$

According to the shape of the scraper conveyor, the left and right supporting sliding shoes must rotate around points $\mathrm{O} 1$ and $\mathrm{O} 2$, respectively; thus, they affect the shearer body pitch angle.

\subsubsection{Coupling Relationship between Guide Sliding Shoes and the Shape of Pin Rails}

(1) Analysis of the Shape of Pin Rails. Due to a small change in the vertical inclination angle, the connecting pin rails are bent along the shape of the two adjacent middle troughs, and their pitch angle is half the sum of the horizontal inclination angles of the two adjacent middle troughs.

The horizontal inclination angle of the middle pin rails is given as follows:

$$
\theta_{M i}=\alpha_{i}
$$

The horizontal inclination angle of the connecting pin rails is given as follows:

$$
\theta_{N i}=\frac{\left(\alpha_{i}+\alpha_{i+1}\right)}{2} .
$$

The curvilinear equation of the pin rails can be expressed according to the coordinate of each axle hole; therefore, the equation of the pin rails can be expressed as follows:

$$
\begin{array}{r}
g_{1}(x)=Y_{M X P}(1)+\left(x-X_{M X P}(1)\right) * \tan \theta_{M 1} \\
X_{M X P}(1) \leq x \leq X_{N X P}(1) \\
g_{2}(x)=Y_{N X P}(1)+\left(x-X_{N X P}(1)\right) * \tan \theta_{N 1} \\
X_{N X P}(1)<x \leq X_{M X P}(2)
\end{array}
$$




$$
\begin{gathered}
g_{2 i-1}(x)=Y_{M X P}(i)+\left(x-X_{M X P}(i)\right) * \tan \theta_{M i} \\
X_{M X P}(i) \leq x \leq X_{N X P}(i) \\
g_{2 i}(x)=Y_{N X P}(i)+\left(x-X_{N X P}(i)\right) * \tan _{N i} \\
X_{N X P}(i)<x \leq X_{M X P}(i+1),
\end{gathered}
$$

where $\left(X_{M X P}(i), Y_{M X P}(i)\right)$ and $\left(X_{N X P}(i), Y_{N X P}(i)\right)$ are the coordinates of the left and right axle holes of middle trough $i$, respectively.

(2) Coordinate Analysis of Walking Wheels. Coupled with the curve of the pin rails, points $D 1$ and $D 2$ can be calculated on the basis of points $\mathrm{O} 1$ and $\mathrm{O} 2$. The shearer body pitch angle is verified and the vertical inclination angle is adjusted until the shearer body pitch angle is equal to the value calculated in Section 2.4.1. In contrast, the vertical inclination angle must be compensated.

\subsection{Fusion Strategy of Positioning and Attitude Based on the Information Fusion Strategy}

2.6.1. Information Fusion Strategy. The SINS and tilt sensors are used to measure two variables: the shearer body pitch angle and the horizontal and vertical inclination angles of every middle trough.

At different temperatures and in different environments, electromagnetic interference easily affects the sensors by causing noise and error; this means that the drifting phenomenon of original data could possibly occur in a single sensor and that the true operation state of shearer and conveyor may not be accurately displayed. Thus, the information fusion algorithm was used to improve the two variables using two sensors.

The theoretical values were obtained using the simulation result and the information fusion value of the middle trough obtained by two sensors, and the shearer body pitch angles were corrected and fused with the information fusion algorithm in real time.

Therefore, the multisensor information fusion algorithm, which uses multiple data collected from multiple sensors at different times, marks the actual state of two devices.

The premise of the adaptive algorithm is the batch algorithm, so it is necessary to explain it.

The batch estimation algorithm and adaptive weighted fusion algorithm are used for calculation.

(1) Batch Estimation Algorithm. $p$ measurement datum $\left[\gamma_{1}, \gamma_{2}, \ldots, \gamma_{p}\right]$, collected by one sensor at regular intervals, is divided into two groups:

(1) When $p$ is odd, the two groups are $\left[\gamma_{1}, \gamma_{2}, \ldots, \gamma_{(p+1) / 2}\right]$ and $\left[\gamma_{(p+1) / 2}, \gamma_{(p+1) / 2+1}, \ldots, \gamma_{p}\right]$.

(2) When $p$ is even, the two groups are $\left[\gamma_{1}, \gamma_{2}, \ldots, \gamma_{p / 2}\right]$ and $\left[\gamma_{p / 2+1}, \gamma_{p / 2+2}, \ldots, \gamma_{p}\right]$.
Taking the second case as an example, we analyzed the following.

The arithmetic mean $\bar{\gamma}_{1}$ and the mean square deviation $\sigma_{1}$ of the first set measurements are

$$
\begin{aligned}
\bar{\gamma}_{1} & =\frac{1}{p / 2} \sum_{i=1}^{p / 2} \gamma_{i} \\
\sigma_{1} & =\sqrt{\frac{1}{p / 2-1} \sum_{i=1}^{p / 2}\left(\gamma_{i}-\bar{\gamma}_{1}\right) .}
\end{aligned}
$$

The arithmetic mean $\bar{\gamma}_{1}$ and the mean square deviation $\sigma_{1}$ of the second set measurements are

$$
\begin{aligned}
& \bar{\gamma}_{2}=\frac{1}{p / 2} \sum_{i=p / 2+1}^{p} \gamma_{i} \\
& \sigma_{2}=\sqrt{\frac{1}{p / 2-1} \sum_{i=p / 2+1}^{p}\left(\gamma_{i}-\bar{\gamma}_{1}\right) .}
\end{aligned}
$$

The batch estimation $\bar{\gamma}$ and variance $\sigma^{2}{ }_{i}$ of the single sensor could be calculated using the following formula:

$$
\begin{aligned}
& \bar{\gamma}=\frac{\sigma_{2}{ }^{2} \bar{\gamma}_{1}+\sigma_{1}{ }^{2} \bar{\gamma}_{2}}{{\sigma_{1}}^{2}+\sigma_{2}{ }^{2}} \\
& \sigma^{2}=\frac{\sigma_{1}{ }^{2} \cdot{\sigma_{2}}^{2}}{{\sigma_{1}{ }^{2}+{\sigma_{2}}^{2}}^{2}} .
\end{aligned}
$$

The angles calculated by the above algorithms were taken as the accurate results, using which the next step was calculated and analyzed.

Prior knowledge of the tilt sensor and SINS was not required, and the adaptive weighted fusion algorithm could be obtained using the value of the batch estimation angle. Working independently, every angle measured by the tilt sensor or SINS is interfered with by factors such as noise and vibration; therefore, the angle value calculated by the optimal angle is random and could be expressed as follows:

$$
\gamma_{m}-\left(u_{m}, \sigma_{m}\right)
$$

where $u_{m}$ is the expected value and $\sigma_{m}$ is the variance.

Mutually independent of each other, the weighting factors of the tilt sensor, $W_{1}, W_{2}, \ldots, W_{m}$ and $\gamma_{1}, \gamma_{2}, \ldots, \gamma_{m}$, are used to perform information fusion; therefore, $\gamma$, the value of integration, needs to satisfy the following relations:

$$
\begin{aligned}
\gamma & =\sum_{i=1}^{m} W_{i} \bar{\gamma}_{i} \\
\sum_{i=1}^{m} W_{i_{i}} & =1 .
\end{aligned}
$$

The optimal weighting factor corresponding to the minimum total variance is obtained using the following formula:

$$
W_{i}=\frac{1}{\sigma_{i}^{2} \sum_{i=1}^{z}\left(1 / \sigma_{i}^{2}\right)} .
$$


TABLE 2: The shearer body pitch angle measured by tilt sensors and SINS (units: degrees).

\begin{tabular}{|c|c|c|c|c|c|c|c|c|c|c|}
\hline \multirow{3}{*}{ Type } & \multicolumn{10}{|c|}{ Value } \\
\hline & \multicolumn{5}{|c|}{ Group 1} & \multicolumn{5}{|c|}{ Group 2} \\
\hline & 1 & 2 & 3 & 4 & 5 & 6 & 7 & 8 & 9 & 10 \\
\hline SINS & 13.52 & 13.61 & 13.63 & 13.67 & 13.53 & 13.49 & 13.52 & 13.67 & 13.69 & 13.63 \\
\hline Tilt sensor & 13.69 & 13.70 & 13.90 & 13.84 & 13.84 & 13.69 & 13.71 & 13.82 & 13.86 & 13.87 \\
\hline
\end{tabular}

TABLE 3: Measured values for the SINS and tilt sensor and fusion values (units: degrees).

\begin{tabular}{lccc}
\hline & & Tilt sensor & SINS \\
\hline \multirow{2}{*}{ Group 1 } & Mean value & 13.794 & 13.592 \\
& Mean square deviation & 0.0088 & 0.0042 \\
Group 2 & Mean value & 13.790 & 13.61 \\
& Mean square deviation & 0.0071 & 0.0081 \\
Batch estimation algorithm & Fusion value & 13.792 & 13.594 \\
& Variance & $5.58 e-5$ & $1.39 e-5$ \\
Adaptive weighted fusion algorithm & Fusion value & 0.354 & 13.664 \\
\end{tabular}

The acquisition frequency of the sensor is determined to be $50 \mathrm{~ms}$. Owing to the shearer haulage speed being generally within the range of $6-8 \mathrm{~m} / \mathrm{min}$, the walking length is small at $0.5 \mathrm{~s}$. Therefore, the 10 sets of data collected on the tilt sensor and SINS (Table 2) were used infusion and batch fusion, respectively; then, the accurate shearer position relative to the scraper conveyor by the adaptive weighted fusion could be obtained. In this paper, the fusion values obtained using the adaptive weighted fusion algorithm are shown in Table 3.

In this way, a series of data is calculated as shown in Table 4.

2.6.2. Reverse Mapping Method Based on Prior Knowledge. By considering this result obtained by the simulation as prior knowledge, the fusion value of the shearer body pitch angle, obtained using two sensors in real time, corresponds to the reverse shape of the scraper conveyor. In particular, some key inflection positions must be corrected in order to be determined according to the measured value.

As shown in Figure 8, the theoretical curve is first divided into some blocks corresponding to several stages, including $A, B, \ldots, M$ and boundary points marked as $a^{\prime}, b^{\prime}, \ldots, m^{\prime}$.

From prior experience, in the actual operation of the shearer, some points such as $a^{\prime}, b^{\prime}, \ldots, m^{\prime}$ are used to correct and verify the theoretical points in real time, including points $a, b, \ldots, m$. Thus, every interval can be determined; then, the shearer position is reversely mapped to the shape of the scraper conveyor.

\subsection{Planning Software Based on Unity3d}

2.7.1. VR Simulation Software. The models were obtained using the UG software and could access the Unity3d software through model repairing and conversion. The virtual scene

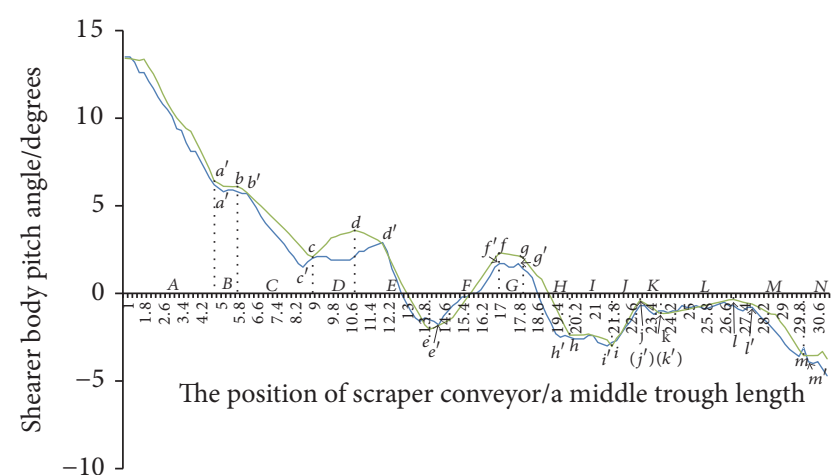

Measurement curve
Theoretical curve

FIGURE 8: Reverse mapping method.

was arranged according to specific rules. By integrating all the algorithms, this software could conduct various simulations under different conditions. A visual GUI was responsible for setting some simulation parameters, which included body length and structural parameters. The real-time processing datum could be output to an XML file, which was easy to analyze, as shown in Figure 9.

The shape of the scraper conveyor could be estimated using the input parameters of every middle trough. To coordinate the virtual shape of the scraper conveyor, the walking position and the attitude of the shearer were calculated backstage in real time. The shearer position was calculated according to the virtual shearer haulage speed, which was decided by an increment, and the shearer position was reversely mapped to the shape of the scraper conveyor. 
TABLE 4: The measured value of SINS and the tilt sensor and the fusion value (units: degrees).

\begin{tabular}{|c|c|c|c|}
\hline Number & SINS & Tilt sensor & Fusion value \\
\hline (1) & 13.6 & 13.79 & 13.664 \\
\hline (2) & 13.2 & 13.31 & 13.233 \\
\hline (3) & 14.3 & 14.21 & 14.273 \\
\hline (4) & 12.9 & 12.91 & 12.903 \\
\hline (5) & 12.4 & 13.31 & 12.673 \\
\hline (6) & 5.9 & 6.12 & 5.966 \\
\hline (7) & 8.3 & 8.07 & 8.231 \\
\hline (8) & 4.2 & 4.01 & 4.143 \\
\hline (9) & 5.7 & 5.33 & 5.589 \\
\hline (10) & 4.4 & 4.6 & 4.46 \\
\hline (11) & 0.3 & 0.83 & 0.459 \\
\hline (12) & 1.3 & 1.46 & 1.348 \\
\hline (13) & 8.3 & 8.74 & 8.432 \\
\hline (14) & 1.2 & 1.29 & 1.227 \\
\hline (15) & -0.7 & 0.38 & -0.376 \\
\hline (16) & 0 & 0.2 & 0.06 \\
\hline (17) & -5.6 & -5.63 & -5.609 \\
\hline (18) & 1.3 & 0.56 & 1.078 \\
\hline (19) & 5.5 & 5.28 & 5.434 \\
\hline (20) & 0.2 & 0.07 & 0.161 \\
\hline (21) & 0.6 & 0.08 & 0.444 \\
\hline (22) & 0.4 & 0.16 & 0.328 \\
\hline (23) & -8.2 & -8.8 & -8.38 \\
\hline (24) & 0.7 & 0.15 & 0.535 \\
\hline (25) & -1 & -1.42 & -1.126 \\
\hline (26) & -0.8 & -1.21 & -0.923 \\
\hline (27) & -1.8 & -1.46 & -1.698 \\
\hline (28) & -0.2 & -0.73 & -0.359 \\
\hline (29) & 0.1 & -0.32 & -0.026 \\
\hline (30) & -0.9 & -1.3 & -1.02 \\
\hline (31) & -1.3 & -1.45 & -1.345 \\
\hline (32) & -2.2 & -2.6 & -2.32 \\
\hline (33) & -6.6 & -7.08 & -6.744 \\
\hline$(34)$ & -1.2 & -1.07 & -1.161 \\
\hline$(35)$ & -8.4 & -8.72 & -8.496 \\
\hline
\end{tabular}

\section{Experiments and Results}

3.1. Test Prototype. Three machines in our laboratory were selected as the research objects. The type of the scraper conveyor was SGZ764/630. The type of the shearer was MGTY250/600, and its body length was 5,327 $\mathrm{mm}$.

Therefore, a prototype shearer and scraper conveyor whose sizes were $13.3 \%$ of the size of the original equipment were designed and manufactured. This enabled more convenient and faster experimentation (Figure 10). Using the scraper conveyor prototype, we were able to achieve the following: (1) variable shapes of the scraper conveyor could be formed; (2) in a different connection state of the middle troughs, the curve formed by the pin rails directly influenced the running trajectory of the shearer; (3) in a different connection state of the middle troughs, the contacting mode between the support sliding shoe and the coal plate could be simulated; (4) a tilt sensor was installed in the middle position of every middle trough to mark the horizontal and vertical inclination angles in real time.

Using the shearer prototype, we could achieve the following: (1) the shearer body length could be changed; (2) coupled with the coal plate, the supporting sliding shoes could selfadapt; (3) two walking wheels were perfectly replaced by two tires, which could simulate the movement of the shearer; (4) a SINS device and a double-axis tilt sensor were installed in the position of the left supporting sliding shoe.

3.2. Static Experiment. The shape of the scraper conveyor prototype was placed as in Figure 10(a), and tilt sensors were installed on every middle trough. Each middle trough was marked with five key points, which divided the middle trough into five parts on an average.

The shearer position is successively decided at every key point belonging to the five key points of each middle trough. Series values of the shearer body pitch angle were read and recorded at every key point.

The datum of every middle trough tilt angle measured by the tilt sensors and SINS was imported to the Unity3d simulation software, and two simulation curves were output. The two theoretical curves of the shearer body pitch angle measured by the Unity3d simulation software and the two actual curves of the shearer body pitch angle measured by the two sensors are shown in Figure 11.

As we can see from Figure 11, the variation trend of the shearer body pitch angle is basically the same as that observed in the theoretical analysis; in addition, the maximum difference is $0.53^{\circ}$. The positioning error of the shearer was less than 0.38 times the middle trough length.

3.3. Dynamic Experiment. The static experiment cannot determine the properties and measurement accuracy of the sensors in the actual process of dynamic operation. Therefore, it was necessary to conduct a dynamic experiment in order to study the dynamic operation properties of the two types of sensors under the condition in which the shearer prototype could operate along with the shape of the scraper conveyor prototype automatically.

After pressing the operation button, the shearer started running, and the shearer body pitch angle in the running process was recorded using two types of sensors in real time.

After selecting the shearer body length as $5,327 \mathrm{~mm}$, the test was conducted five times. The comparison results of the measurement values obtained using the two types of sensors and the theoretical values obtained using the VR software are shown in Figures 12 and 13.

The analysis showed that the tilt sensor was more fluctuant in the process of shearer dynamic operation and that it was easily disturbed by environmental noise. Moreover, 
TABLE 5: Comparison of experimental results of shearer positioning (units: a middle trough length).

\begin{tabular}{|c|c|c|c|}
\hline Theoretical value & $\begin{array}{l}\text { Shearer body pitch angle } \\
\text { measured by the tilt sensors }\end{array}$ & $\begin{array}{l}\text { Shearer body pitch angle } \\
\text { measured by SINS }\end{array}$ & $\begin{array}{l}\text { Shearer body pitch angle } \\
\text { measured according to the } \\
\text { fusion value }\end{array}$ \\
\hline Theoretical value measured by the tilt sensors & 0.73 & 0.59 & 0.42 \\
\hline Theoretical value measured by SINS & 0.67 & 0.49 & 0.45 \\
\hline $\begin{array}{l}\text { Theoretical value measured according to the } \\
\text { fusion value }\end{array}$ & 0.53 & 0.47 & 0.38 \\
\hline
\end{tabular}

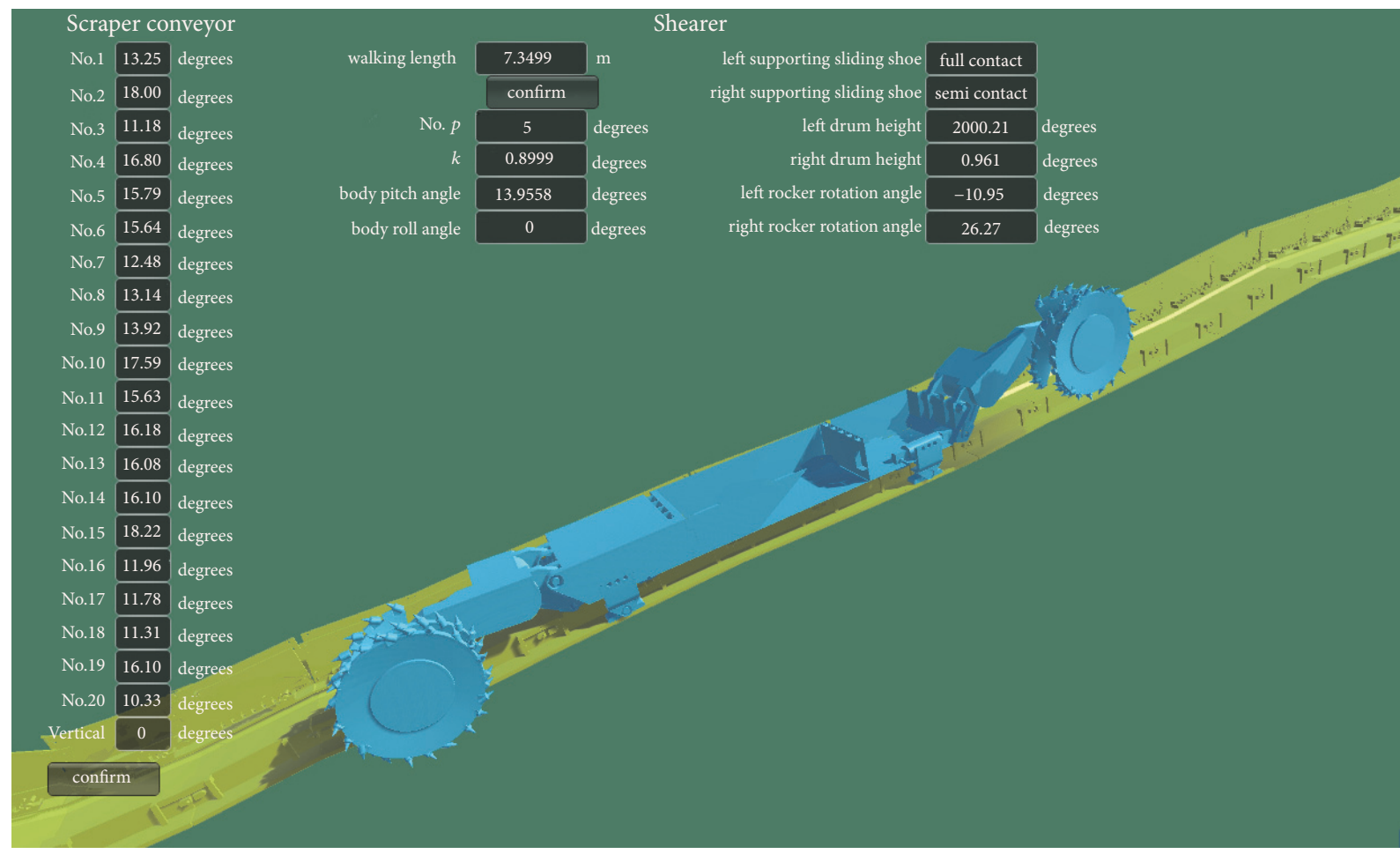

FIGURE 9: Interface of the Unity3d simulation software under complex conditions.

owing to the interdesign of filtered characteristic, the SINS showed good seismic performance.

The variation trend of the shearer body pitch angle was basically the same as that observed in the theoretical analysis. However, the deviations between the two sensors and the theoretical values were greater than those obtained in the static test. Positioning correction, caused by the numerically measured value, may lead to a location error. Therefore, it was necessary to predict and correct the result in real time using the adaptive information fusion algorithm. The curves obtained after processing are shown in Figure 14.

According to the analysis result obtained using the two sensors, the shearer's position relative to the shape of the scraper conveyor can be reversely inferred. After processing with the adaptive fusion algorithm, the position of the shearer could meet the high level of positioning accuracy under the static condition, which was 0.38 times the middle trough length that could be reached (Table 5).

3.4. Experiments under Different Body Lengths. At different shearer body lengths, the variation trends of the shearer body pitch angle were studied. The shearer body lengths were set as $4,500,4,900,5,327,5,800$, and $6,300 \mathrm{~mm}$, which refer to a series of specialized shearer. Under these five conditions, all the experimental results were consistent with the theoretical curves (Figure 15) and two conclusions were drawn.

(1) A shorter shearer body length corresponded to a more backward shearer to the shape of the scraper conveyor and was more sensitive to terrain changes; a longer shearer body length corresponded to an earlier adaptation of the shearer to terrain changes and the shearer being more insensitive to terrain changes. 


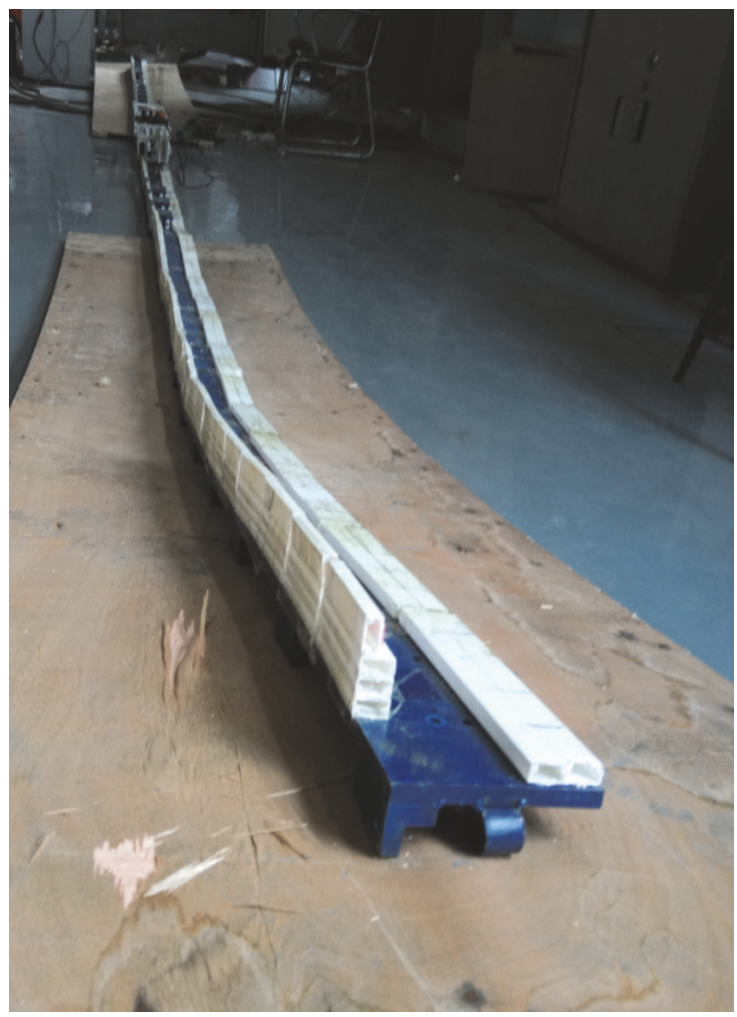

(a)

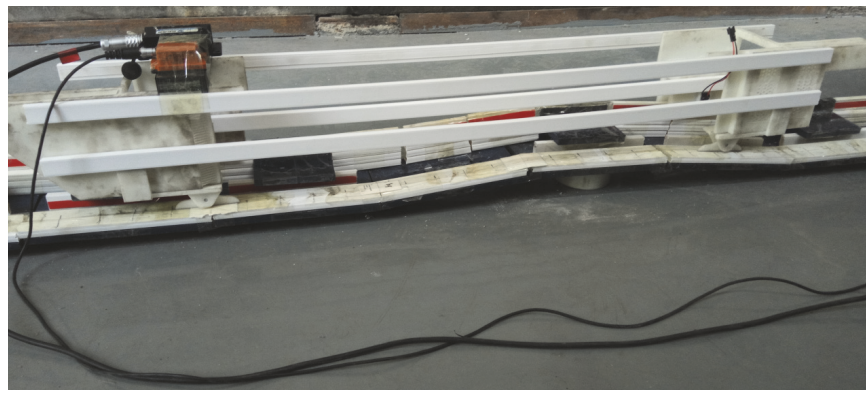

(e)

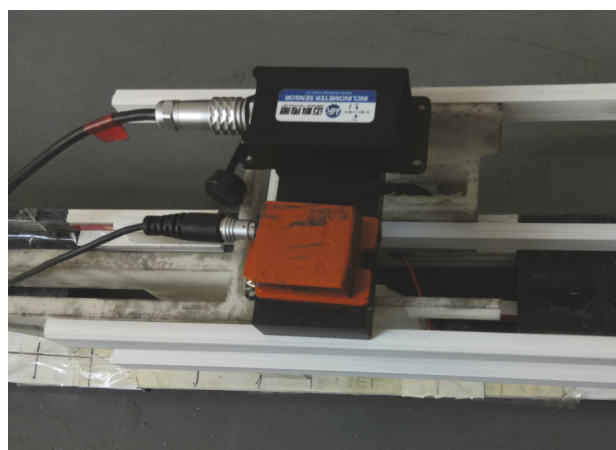

(b)

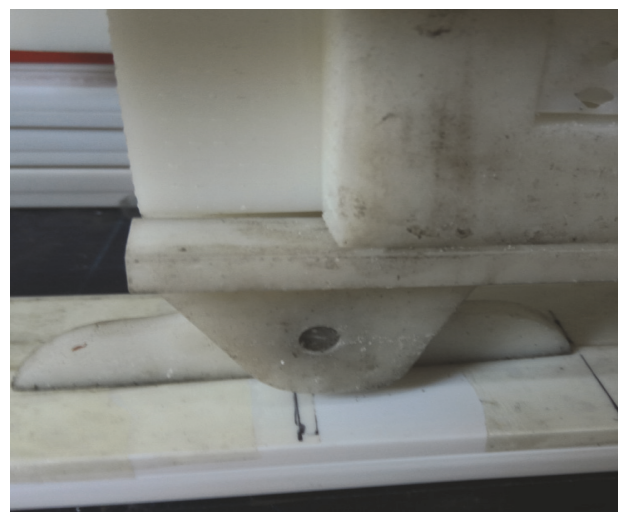

(c)

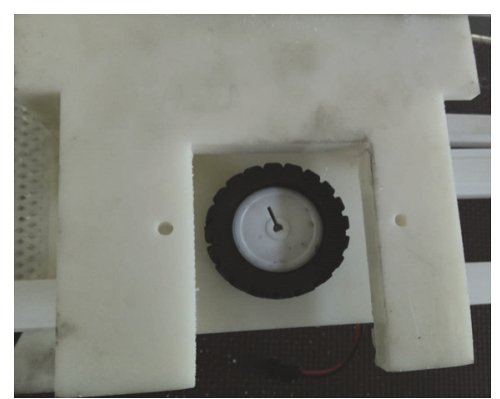

(d)

FIGURE 10: (a) Shape of the scraper conveyor; (b) the two sensors installed in the shearer body; (c) the supporting sliding shoe; (d) the walking wheel; (e) the shearer prototype.

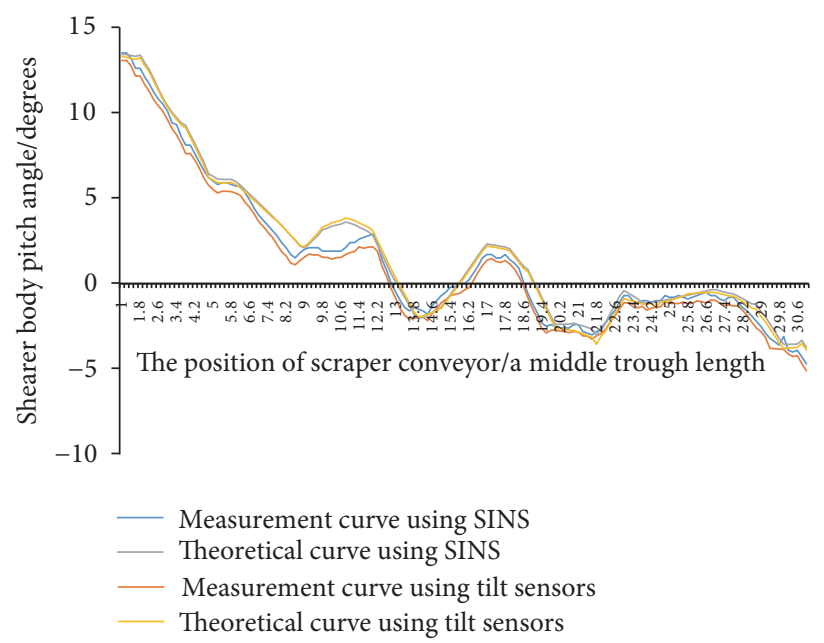

Figure 11: Results of the static test. 


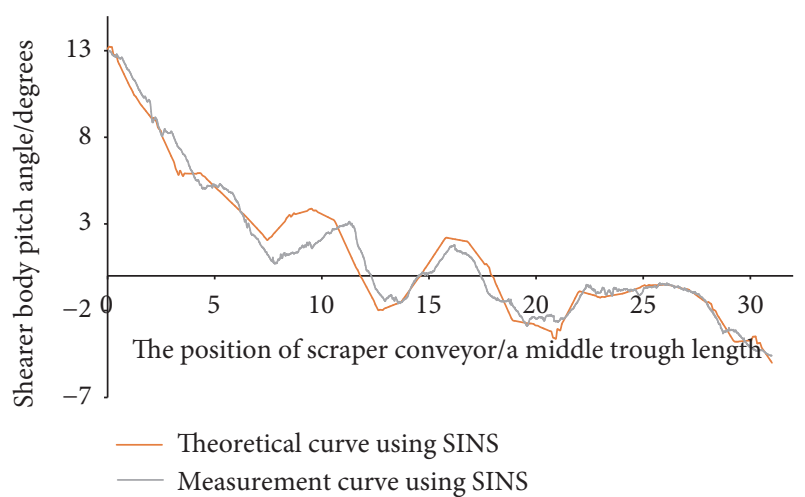

FIGURE 12: Comparison of the results obtained using SINS with the theoretical results.

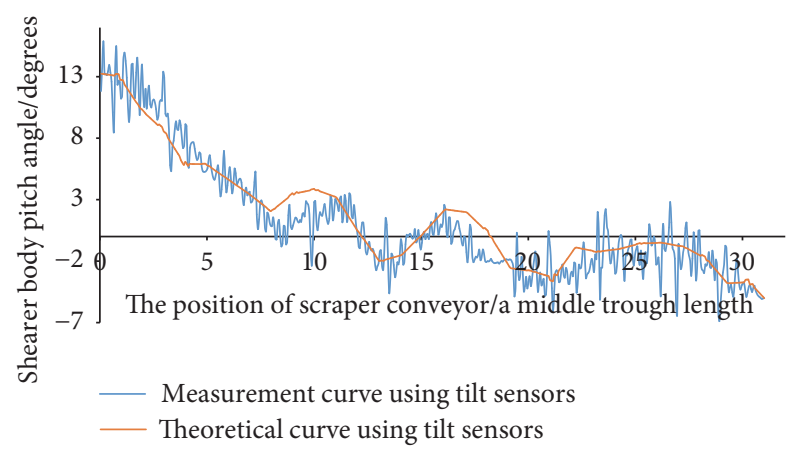

FIGURE 13: Comparison of the results obtained using the tilt sensors with the measurement results.

(2) The longer the shearer body length, the smaller the relative change in the pitching angle under the same shape of the scraper conveyor.

\section{Conclusions}

In this study, a joint positioning and attitude solving method was proposed and investigated for shearer and scraper conveyor under complex conditions. The following conclusions were drawn.

(1) This method can provide more precise dynamic monitoring for the operation of shearer and scraper conveyor. By obtaining the shape of the scraper conveyor in real time, the shearer can be used in advance to predict and regulate the operating attitude in the current cycle.

(2) Based on this method, the cutting trajectory of the front and rear drums can be calculated in real time, providing strong support for the memory cutting method in a fully mechanized coal-mining automation face.

(3) No error accumulated. Hence, this positioning method of the shearer could integrate existing positioning methods, including the SINS positioning method, infrared positioning method, walking shaft encoder positioning method, and UWB wireless sensor positioning method.

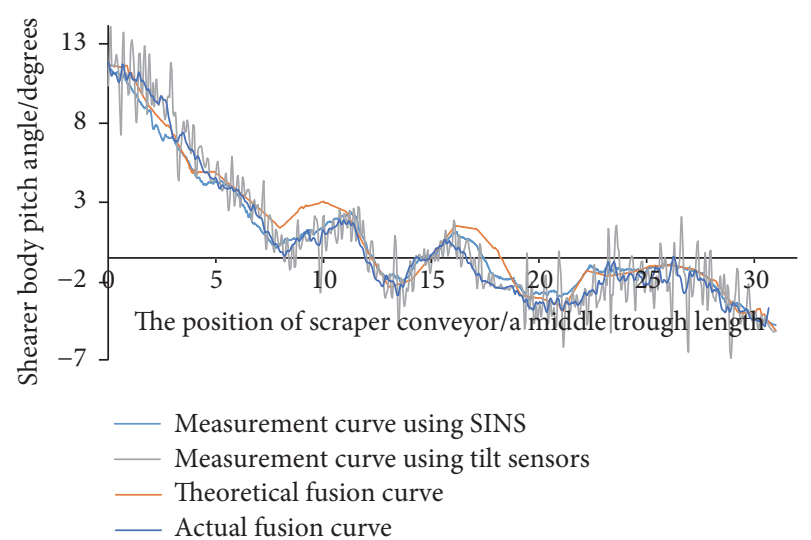

Figure 14: Theoretical values and fusion values of the two sensor measurements.

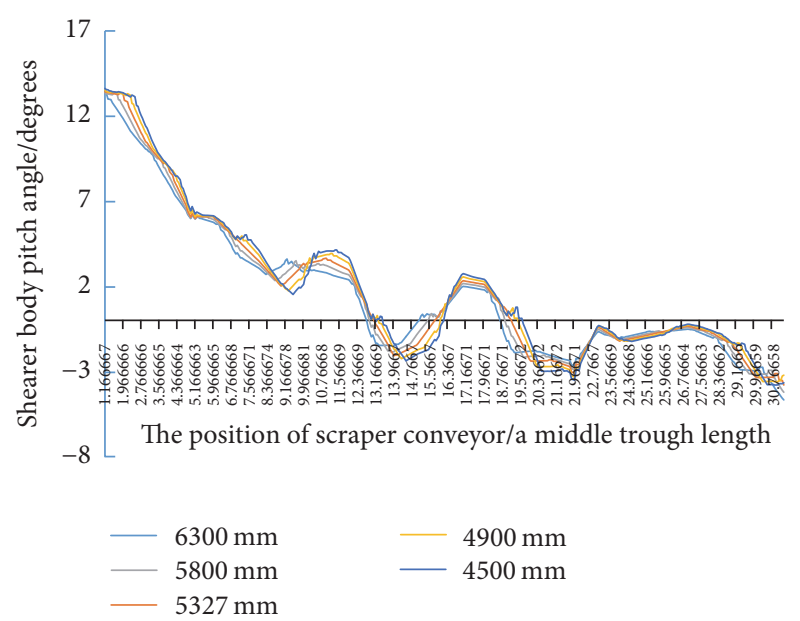

FIGURE 15: Variation trend of the shearer body pitch angle under different shearer body lengths.

These methods realize a more precise positioning for the shearer in actual composite conditions.

(4) This method provides support for the 3D coordinated positioning of fully mechanized coal-mining equipment.

\section{Conflicts of Interest}

The authors declare that there are no conflicts of interest regarding the publication of this paper.

\section{Acknowledgments}

This work was supported by Shanxi Postgraduate Education Innovation Project under Grant 2017BY046, Shanxi Scholarship Council of China under Grant 2016-043, Program for the Outstanding Innovative Teams of Higher Learning Institutions of Shanxi under Grant 2014, and Natural Science Fund of Shanxi Province under Grant 201601D011050. 


\section{References}

[1] P. Przystalka and A. Katunin, "A concept of automatic tuning of longwall scraper conveyor model," in Proceedings of the Federated Conference on Computer Science and Information Systems (FedCSIS '16), pp. 11-14, Gdansk, Poland, September 2016.

[2] K. Cenacewicz and A. Katunin, "Modeling and simulation of longwall scraper conveyor considering operational faults," Studia Geotechnica et Mechanica, vol. 38, no. 2, pp. 15-27, 2016.

[3] O. Stoicuţă and T. Pană, "Modeling and simulation of the coal flow control system for the longwall scraper conveyor," Annals of the University of Craiova, Electrical Engineering Series, vol. 40, pp. 101-108, 2016.

[4] A. Stentz, M. Ollis, S. Scheding et al., "Position measurement for automated mining machinery," in Proceedings of the International Conference on Field and Service Robotics, pp. 299-304, Agapito Associates, Pittsburgh Pa, USA, August 1999.

[5] S. K. Michael and D. W. Hainsworth, "Outcomes of the landmark long-wall automation project with reference to ground control issues," in Proceedings of the 24th International Conference on Ground Control in Mining, pp. 66-73, Agapito Associates, Morgantown, WVa, USA, 2005.

[6] G. A. Einicke, J. C. Ralston, C. . Hargrave, D. C. Reid, and D. W. Hainsworth, "Longwall mining automation: an application of minimum-variance smoothing," IEEE Control Systems Magazine, vol. 28, no. 6, pp. 28-37, 2008.

[7] C. S. Liu, "Mathematic principle for memory cutting on drum shearer," Journal of Heilongjiang Institute of Sciences and Technology, vol. 20, pp. 85-90, 2010.

[8] L. Yin, J. Y. Liang, Z. C. Zhu et al., "Simulation analysis of coal floor undulation based on long wall working face," Coal Mine Machinery, vol. 31, pp. 75-77, 2010.

[9] P. L. Wu and N. P. Niu, "Research and analysis of the relationship between the angle of scraper and the working face," Electronics World, vol. 16, pp. 98-99, 2012.

[10] W. F. Jiang, S. B. Li, J. F. Niu et al., "A scraper conveyor attitude control system and control method based on wireless three-dimensional gyroscope technology," China Parent, CN 102431784 A, 2012.

[11] Y. L. Suo, "Mechanism and control of the floor undulation of the slicing fully mechanized faces," Journal of Xian Mining Institute, vol. 19, pp. 101-104, 1999.

[12] R. G. Zhang and D. W. Si, "Analysis on angle of tilt and offset angle influencing on characteristic of scraper conveyor," Zhongzhou Coal, vol. 12-13, 2005.

[13] Z. P. Xu, Study on the key technologies of self-adaptive cutting for shearer [Dissertation], China University of Mining and Technology, Xuzhou, China, 2011.

[14] C. S. Liu and J. G. Chen, "Mathematic model of memory cutting for coal shearer based on single demo knife," Coal Sciences and Technology, vol. 39, pp. 71-73, 2011.

[15] X. L. Su, Z. S. Lian, and C. Y. Zhang, "Research on mathematic model of memory cutting for coal shearer based on double demo knife," Coal Mine Machinery, vol. 35, pp. 55-57, 2014.

[16] Z. L. Ge, Study on shearer self-adaptive control based on its absolute position and attitude [Dissertation], China University of Mining and Technology, Xuzhou, China, 2015.

[17] S. Feng, Study on the key technologies of relative position fusion and correction system between shearer and hydraulic support [Dissertation], China University of Mining and Technology, Xuzhou, China, 2015.
[18] B. Sofman, J. A. Bagnell, A. Stentz et al., Terrain classification from aerial data to support ground vehicle navigation [Dissertation], Carnegie Mellon University, Pittsburgh, Pa, USA, 2006.

[19] Y. Hai, L. I. Wei, C. M. Luo et al., "Experimental study on position and attitude technique for shearer using SINS measurement," Journal of China Coal Society, vol. 39, pp. 25502556, 2014.

[20] D. C. Reid, D. W. Hainsworth, J. C. Ralston et al., "Shearer guidance: a major advance in longwall mining," in Field and Service Robotics, vol. 28, pp. 469-476, Springer, Berlin, Germany, 2006.

[21] J. Ralston, D. Reid, C. Hargrave, and D. Hainsworth, "Sensing for advancing mining automation capability: A review of underground automation technology development," International Journal of Mining Science and Technology, vol. 24, no. 3, pp. 305310, 2014.

[22] M. Dunn, D. Reid, and J. Ralston, "Control of automated mining machinery using aided inertial navigation," in Machine Vision and Mechatronics in Practice, pp. 1-9, Springer, Berlin, Germany, 2015.

[23] D. C. Reid, M. T. Dunn, P. B. Reid, and J. C. Ralston, "A practical inertial navigation solution for continuous miner automation," in Proceedings of the 12th Coal Operators' Conference, University of Wollongong the Australasian Institute of Mining and Metallurgy, pp. 114-119, The Australasian Institute of Mining and Metallurgy, Wollongong, Australia, 2012.

[24] S. Hao, S. Wang, R. Malekian, B. Zhang, W. Liu, and Z. Li, "A geometry surveying model and instrument of a scraper conveyor in unmanned longwall mining faces," IEEE Access, vol. 5, pp. 4095-4103, 2017.

[25] A. Li, S. Q. Hao, S. B. Wang et al., "Experimental study on shearer positioning method based on SINS and Encoder," Coal Science and Technology, vol. 44, pp. 95-100, 2016.

[26] B. H. Ying, W. Li, C. M. Luo et al., "Experimental study on combinative positioning system for shearer," Chinese Journal of Sensors and Actuators, pp. 260-264, 2015.

[27] Q. Fan, W. Li, J. Hui et al., "Integrated positioning for coal mining machinery in enclosed underground mine based on SINS/WSN," The Scientific World Journal, vol. 2014, Article ID 460415, 12 pages, 2014.

[28] V. Henriques and R. Malekian, "Mine safety system using wireless sensor network," IEEE Access, vol. 4, pp. 3511-3521, 2016.

[29] J. C. Ralston, "Automated longwall shearer horizon control using thermal infrared-based seam tracking," in Proceedings of the IEEE International Conference on Automation Science and Engineering, vol. 8, pp. 20-25, August 2012.

[30] S. R. Ge, Z. S. Su, A. Li et al., "Study and application of positioning and orientiation of shearer based on geographic information system," Journal of China Coal Society, vol. 40, pp. 2503-2508, 2015.

[31] Z. Zhang, S. B. Wang, B. Y. Zhang et al., "Shape detection of scraper conveyor based on shearer trajectory," Journal of China Coal Society, vol. 40, pp. 2514-2521, 2015. 


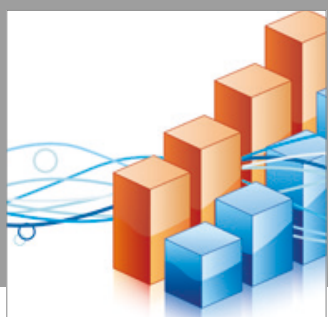

Advances in

Operations Research

vatersals

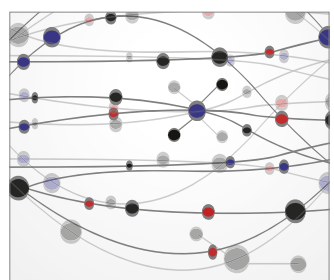

\section{The Scientific} World Journal
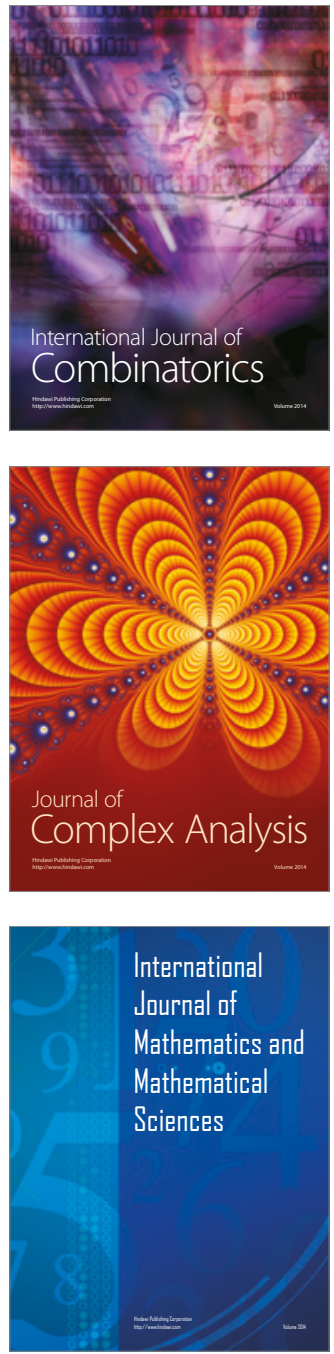
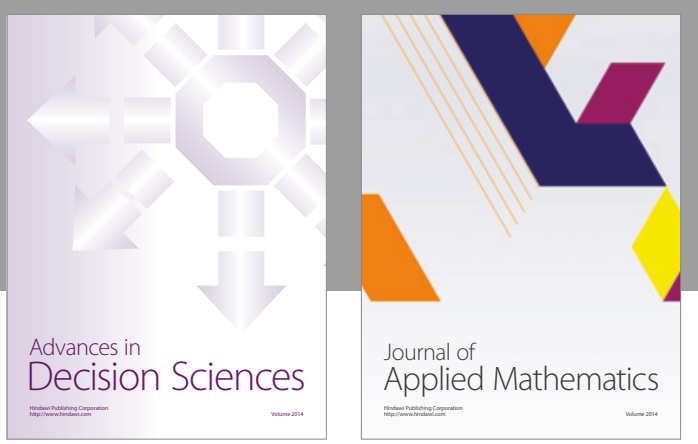

Algebra

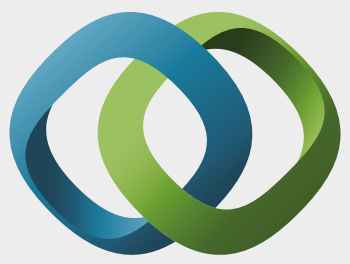

\section{Hindawi}

Submit your manuscripts at

https://www.hindawi.com
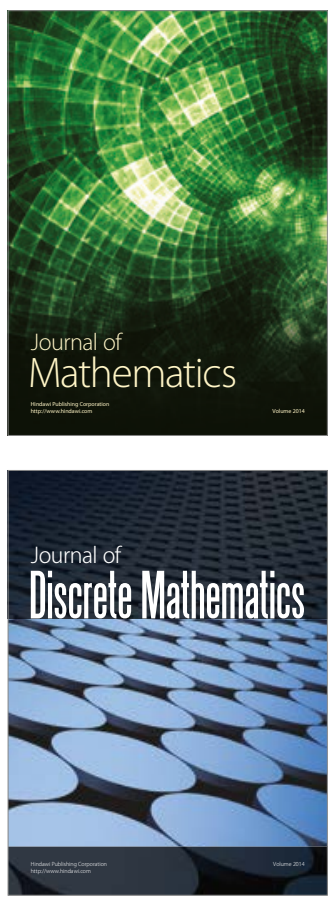

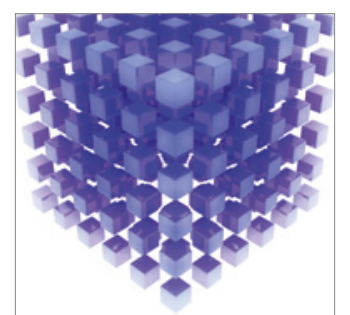

Mathematical Problems in Engineering
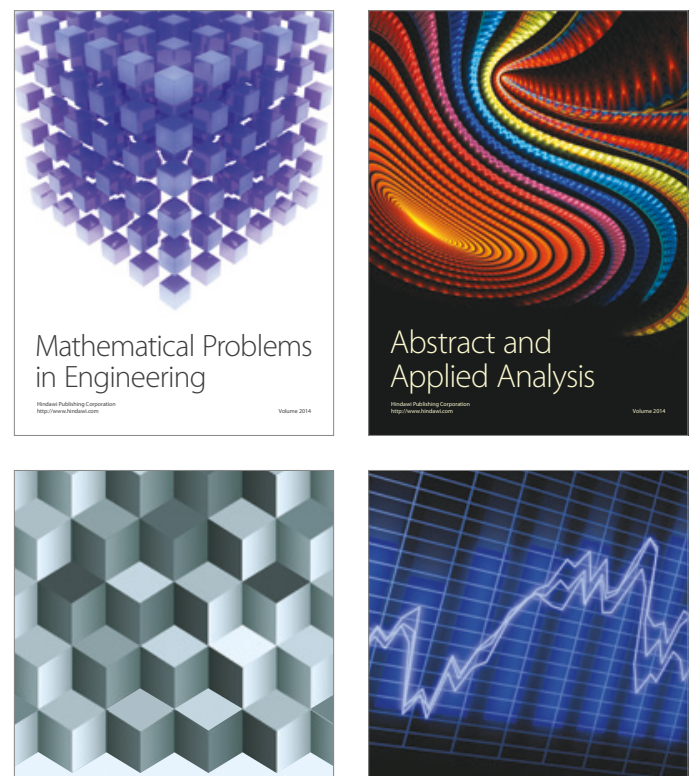

Journal of

Function Spaces

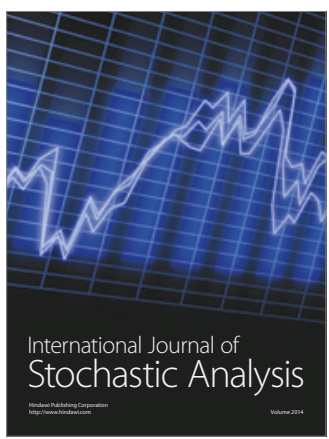

Probability and Statistics
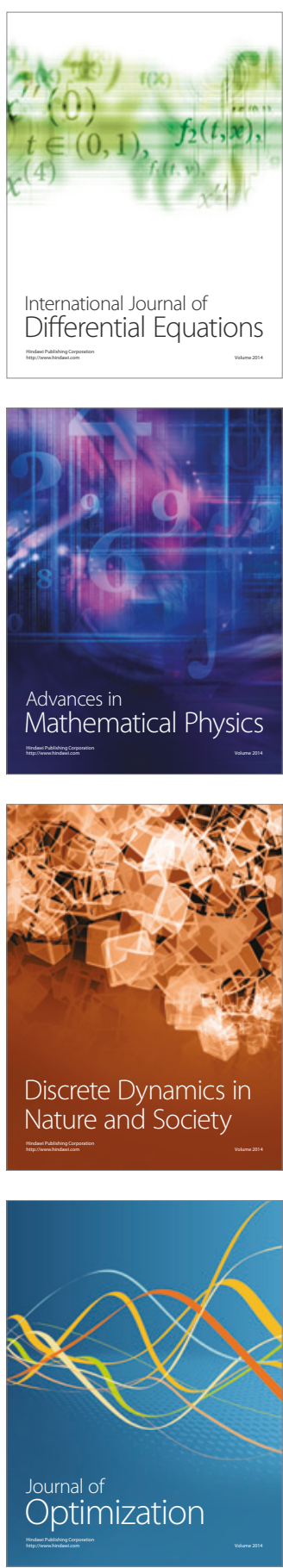